\title{
Vênus: de Roma a Vila Rica
}

\author{
Míriam Barcellos Goettems
}

RESUMO: In this paper I undertake an analysis of the references to Venus present in the poetry by Tomás Antônio Gonzaga and in odes by Horace in which similarities and differences between the conceptualizations of the goddess presented by one and another poet are stablished. Hence, it is possible to verify the aplicability of the concept of indirect mimesis as criation according to the arguments posed by the neoclassical theoreticians in relation to the principle of imitation of the classical authors.

PALAVRAS-CHAVE: neoclassicismo, mimese indireta, criação, Vênus, liras de Tomás Antônio Gonzaga, odes de Horácio.

Ponto capital dentre os que compõem o ideário neoclássico — do qual Tomás Antônio Gonzaga é um dos mais eminentes realizadores em língua portuguesa — é o preceito da imitação dos antigos.

Teóricos setecentistas, como Luís Antônio Verney, Correia Garção, Filinto Elísio, Alexander Pope, Ignacio de Luzán e Silva Alvarenga, ressaltam, na esteira de Horácio, Quintiliano e Boileau, o valor da mimese indireta, ou seja, daquele tipo de imitação que incide não sobre os objetos criados pela própria natureza mas sobre aqueles que foram produzidos pela arte. Segundo esses teóricos, tal espécie de imitação, cujo produto final corresponde à recriação de uma realidade já imitada — daí a chamarmos de mimese indireta —, é de importância fundamental para a formação do bom poeta e para a consecução, por este, daquele que deve ser o seu objetivo primacial, isto é, a transformação da poesia em verdadeira imitação da natureza.

Uma compreensão exata dessa valorização positiva que os neoclássicos conferem à mimese indireta exige que se entenda, antes de mais nada, o que significa para eles o processo imitativo.

Correia Garção concebe tal processo como formado, por assim dizer, de dois momentos básicos: um, de preservação de elementos já existentes, e o segundo, de introdução de outros que permitam ao poeta transfigurar os antigos, dando-lhes uma feição nova e, portanto, sua, pessoal.

Universidade Federal do Rio Grande do Sul. 
Em outras palavras, a imitação é um processo dialético em que o antigo e o novo se mesclam para produzir algo que, sem deixar de ser ele mesmo, é, paradoxalmente, um outro. Diz esse preceptista em sua Dissertação III:

"O poeta é senhor da matéria de que trata: se a invenção é toda sua, pode formá-la como lhe parecer; se a pediu emprestada a algum dos antigos poetas, deve, quanto lhe for possível, reduzi-la a tão nova figura que pareça outra e que fique sendo sempre a mesma" (GARÇÃO, 1958, p.138).

De um lado, devemos observar, nessas palavras de Garção, a igualdade de valor concedida às duas alternativas que se colocam ao poeta, igualdade essa que se compreende facilmente tendo em vista que, quer optando por inventar elementos novos, quer escolhendo imitar outros já existentes, o poeta jamais deixará de ser o senhor da matéria de que trata. Por outro lado, a afirmação de que o elemento imitado, a par de se transformar em outro, deve ficar sendo sempre o mesmo condiz integralmente com o pensamento de Horácio, que, ao tratar do modo como devem os poetas representar as personagens por outros criadas, recomenda-lhes "seguir a fama" - "famam sequere" (HORACE, 1961, p.208).

Isso significa que determinadas facetas do caráter de personagens já existentes não podem ser alteradas, sob pena de, perdendo o que as caracteriza de forma mais marcante, deixarem de ser elas mesmas para se transformarem em figuras completamente diferentes, que só mantenham de seu original o nome. Nesse limite, já não mais seria possível falar de imitação, tendo em vista que, faltando o primeiro de seus componentes - a preservação de determinados elementos -, o processo imitativo ficaria incompleto, cedendo, então, lugar à criação em termos absolutos.

No que se refere à exigência de Garção de que o elemento imitado seja reduzido "a tão nova figura que pareça outra", é de salientar que satisfazê-la é algo bem mais fácil do que, à primeira vista, pode parecer. Segundo Luzán, para isso concorrem duas espécies de elementos: de um lado, as condições pessoais dos autores — estudo e gênio, em particular; de outro, os fatores ambientais que os cercam. Para o teórico espanhol, dois escritores nascidos em épocas e em nações distintas terão certamente concepções diversas acerca de pontos idênticos. Por isso, não lhes será difícil transfigurar - como quer Garção - os elementos que tomam por modelo; de certa forma, essa transfiguração é uma decorrência natural das mudanças de contexto, o que possibilita, inclusive, colocar em dúvida o caráter racional da busca do novo pregada por Garção: essa busca precisa mesmo ser realizada conscientemente? Sua simples inserção em outros textos não fará com que tanto passagens quanto personagens adquiram "un no sé qué" — para usarmos palavras de Luzán (LUZÁN, 1974, p.226) — que as fará diferentes do que anteriormente foram? 
As respostas a tais perguntas nos são dadas por um outro preceptista português: Filinto Elísio, para quem a simples introdução de elementos antigos em um novo texto conferirá a eles características peculiares, responsáveis pela unicidade desse texto. Comparando a atividade do poeta à de um escultor, desta forma expressa-se Filinto Elísio:

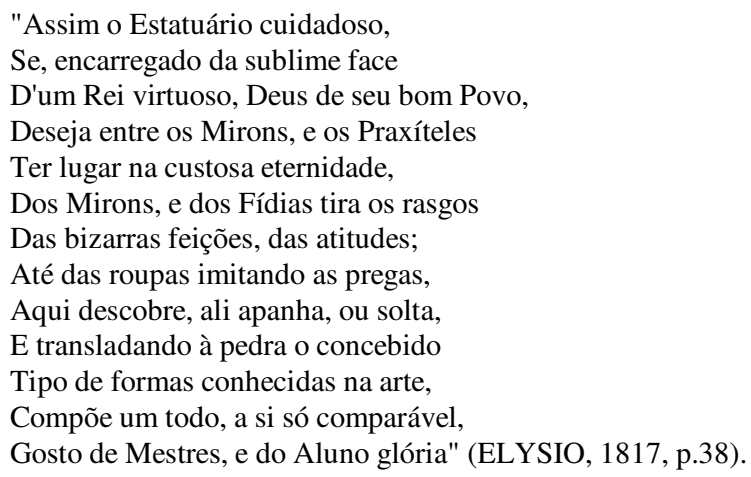

Como se observa, o privilégio que Garção confere à criação dentro da mimese indireta recebe, com Filinto Elísio, um impulso maior. Se, para aquele, a imitação só existe quando novos elementos são deliberadamente introduzidos pelo poeta, para este, ela também é possível quando os dados de que o autor se vale são antigos; isso acontece porque a inserção de tais dados num outro texto confere-lhes nova vida, fazendo com que não passe de ilusão a semelhança que julgamos existir entre ele e o original.

Não obstante essa diferença de concepção, é unívoca a idéia básica que subjaz ao conceito de mimese indireta defendido pelos dois teóricos portugueses: a imitação é produção e não reprodução.

Verificaremos, a seguir, a aplicabilidade desse conceito, através do confronto de referências feitas a Vênus por Tomás Antônio Gonzaga em duas de suas liras - as de número 27 e 25 - com outras existentes em odes de Horácio (a introdução de divindades mitológicas é, como sabemos, uma das formas pelas quais se manifesta a mimese indireta no século XVIII). Partiremos, no exame de cada referência à deusa, do levantamento de dados que a identifiquem com a Vênus horaciana. A partir da análise das semelhanças, voltar-nos-emos para aquilo que marca a diferença e, portanto, a unicidade do elemento analisado em relação ao modelo horaciano.

Vejamos, inicialmente, o que diz a lira 27 de Gonzaga:

"Vou retratar a Marília,

a Marília, meus amores;

porém como? se eu não vejo

quem me empreste as finas cores:

dar-mas a terra não pode;

não, que a sua cor mimosa 
vence o lírio, vence a rosa,

o jasmim e as outras flores.

Ah! socorre, Amor, socorre

ao mais grato empenho meu!

Voa sobre os astros, voa,

traze-me as tintas do céu.

Mas não se esmoreça logo;

busquemos um pouco mais; nos mares talvez se encontrem

cores, que sejam iguais.

Porém, não, que em paralelo

da minha ninfa adorada

pérolas não valem nada, não valem nada os corais.

Ah! socorre, Amor, socorre

ao mais grato empenho meu!

Voa sobre os astros, voa,

traze-me as tintas do céu.

Só no céu achar-se podem tais belezas como aquelas que Marília tem nos olhos, e que tem nas faces belas; mas às faces graciosas, aos negros olhos, que matam, não imitam, nem retratam nem auroras nem estrelas.

Ah! socorre, Amor, socorre ao mais grato empenho meu! Voa sobre os astros, voa, traze-me as tintas do céu.

Entremos, Amor, entremos, entremos na mesma esfera; venha Palas, venha Juno, venha a deusa de Citera.

Porém, não, que se Marília no certame antigo entrasse, bem que a Páris não peitasse, a todas as três vencera.

Vai-te, Amor, em vão socorres

ao mais grato empenho meu;

para formar-lhe o retrato

não bastam tintas do céu" (GONZAGA, 1957, v.1, p.47-8).

Dois fatos relacionados a Vênus — suas ligações com a ilha de Citera e sua participação no episódio do pomo da discórdia - constituem, de forma abrangente, os elementos identificadores da divindade referida por Gonzaga no $4^{\circ}$ verso da última estrofe à que Horácio apresenta em suas odes. 
No que se refere ao primeiro desses fatos, devemos observar, num primeiro momento, que ele subjaz na própria forma com que o poeta designa a deidade: "a deusa de Citera". Num segundo momento, saliente-se que tal designação é análoga à que Horácio utiliza no $5^{\circ}$ verso da ode IV do livro I, onde se refere à divindade como "Cytherea Venus" — "Vênus Citeréia" (HORACE, 1954, p.12). Ambos os poetas remetem-nos, assim, à versão hesiódica do nascimento da deusa, versão essa que explica as ligações de Vênus com a mencionada ilha.

Quanto ao episódio do pomo da discórdia, cumpre salientar que a demonstração do conhecimento que dele tem o poeta árcade não se dá unicamente a partir de uma expressão, encontrando-se diluída pela quase totalidade da última estrofe, especialmente através das menções feitas a Palas, a Juno, à deusa de Citera ao certame antigo e a Páris.

Menos claramente expressa mas não menos inteligível do que a de Gonzaga é a referência feita por Horácio, na ode XV do livro I, à participação de Vênus no mencionado episódio:

"Pastor cum traheret per freta nauibus

Idaeis Helenen perfidus hospitam, ingrato celeris obruit otio

uentos ut caneret fera

Nereus fata: 'Mala ducis aui domum quam multo repetet Graecia milite, coniurata tuas rumpere nuptias et regnum Priami uetus.

Heu, heu, quantus equis, quantus adest uiris sudor! quanta moues funera Dardanae genti! iam galeam Pallas et aegida currusque et rabiem parat.

Nequicquam Veneris praesidio ferox pectes caesariem grataque feminis inbelli cithara carmina diuides; nequicquam thalamo grauis

hastas et calami spicula Cnosii uitabis strepitumque et celerem sequi Aiacem: tamen, heu serus, adulteros crines puluere collines.

Non Laertiaden, exitium tuae gentis, non Pylium Nestora respicis? Vrgent impauidi te Salaminius Teucer, te Sthenelus sciens pugnae, siue opus est imperitare equis, 


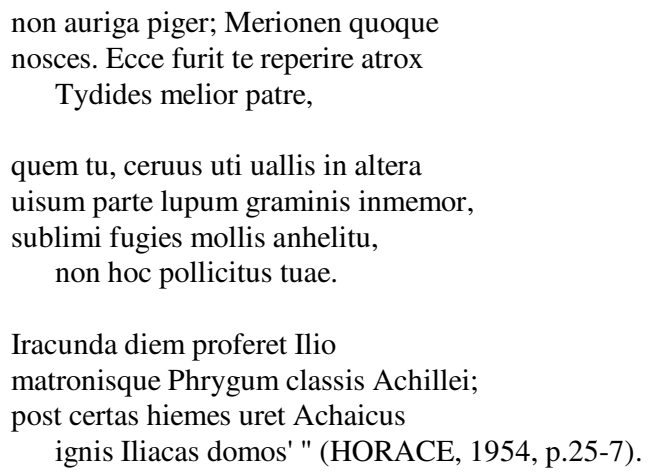

Vejamos a tradução dessa ode em forma narrativa:

"Quando o pérfido pastor arrastava, através dos mares, em naus do Ida, a sua hospedeira Helena, Nereu encerrou, por um intervalo desagradável, os rápidos ventos, a fim de cantar os terríveis destinos: 'Conduzes para tua pátria, sob sinistro agouro, aquela que, conjurada para desmoronar o teu himeneu e o antigo reino de Príamo, a Grécia há de reclamar com numeroso exército. $\mathrm{Oh}$ ! quanto suor custa aos cavalos, quanto aos guerreiros! quantos funerais preparas ao povo de Dárdano! Já Palas apresta seu capacete e sua égide, seu carro e furor. Em vão, altivo com o apoio de Vênus, pentearás tua cabeleira e romperás, com tua cítara efeminada, em cantos agradáveis às mulheres; em vão evitarás, em tua alcova, as terríveis lanças e as pontas (agudas) da(s) seta(s) de Gnosso e o fragor (da batalha) e Ájax pronto para te perseguir; contudo, tardiamente, ah!, sujarás de pó os teus cabelos adúlteros. Não vês (atrás) o filho de Laertes, ruína da tua raça, nem Nestor de Pilos? Intrépidos te perseguem Teucro de Salamina e Estênelo, conhecedor da arte militar; caso seja preciso guiar cavalos, não é um cocheiro indolente. Tu conhecerás também Meríones. Eis que arde por te encontrar o terrível filho de Tideu, mais valente que o pai, de quem tu, covarde, fugirás, ofegante qual cervo que se esquece da grama tendo avistado um lobo no outro lado do vale, não tendo tu prometido isso à tua (Helena). A furiosa frota de Aquiles prolongará a duração de Ílion e das matronas da Frígia; depois de um certo número de invernos, o fogo acaico queimará as moradas de Ílion' ".

A referência, no $1^{\circ}$ verso da $4^{\mathrm{a}}$ estrofe, ao apoio fornecido por Vênus a Páris, é duplamente importante para esta investigação: primeiro, porque nos remete ao episódio propriamente dito do pomo da discórdia, fazendo-nos lembrar que o auxílio da deusa é consequiência do fato de Páris a ter escolhido como a mais bela; segundo, porque, a partir dessa referência, podemos verificar que estamos nos defrontando com uma diversidade de 
usos, feitos por Gonzaga e por Horácio, de um ponto de partida idêntico, o certame antigo, como o denomina o poeta árcade.

É marcante, em todos os momentos que esse episódio envolve, a atuação de Vênus como deusa da beleza e do amor. Como deusa da beleza, ela faz uso de todos os seus atrativos para ofuscar Páris e obter dele o pomo ambicionado. Como deusa do amor, atua no sentido de promover a atração entre Páris e Helena, que se esquece de suas obrigações matrimoniais a fim de seguir, com o jovem, para Tróia.

Ambas as feições de Vênus acorrem-nos à mente quando lemos uma passagem como a escrita por Gonzaga; não só elas, aliás, mas todas as relações que qualquer menção ao episódio do pomo da discórdia nos faz estabelecer com a guerra de Tróia. $\mathrm{O}$ fato de pensarmos em todos esses elementos não nos deve, todavia, impedir de reconhecer que o poeta, na lira 27, não está, de modo algum, preocupado com eles. Vênus não é, por exemplo, ali, deusa do amor: inexiste qualquer referência - ao contrário do que acontece na ode XIX do livro I de Horácio, a ser examinada posteriormente - ao fato de ser ela a responsável pelo sentimento acalentado pelo eu com respeito a Marília. Igualmente não é deusa da beleza, muito embora os seus dotes físicos sejam peça fundamental na engrenagem montada pelo poeta com o fito de enaltecer a formosura de sua amada; essa faceta de Vênus seria ressaltada se, por exemplo, Gonzaga considerasse os predicados de Marília como frutos de um dom da deusa, tal como o faz o vate latino com relação aos possuídos, no passado, por Lice, a quem dirige a ode XIII do livro IV (HORACE, 1954, p.177-8). Ali, após referir as conseqüências funestas que o passar dos anos trouxe para Lice — desfiguram-na os dentes amarelados, as rugas e os cabelos brancos —, o poeta indaga, no verso inicial da $5^{\text {a }}$ estrofe: "Quo fugit Venus?" — "Para onde fugiu Vênus?" (HORACE, 1954, p.177). Essa indagação demonstra bem que, para o eu cantante, a beleza outrora possuída por Lice havia-lhe sido conferida pela deusa. A exemplo do que faz Donaldo Schüler ao referir, em Aspectos estruturais na Ilíada, o argumento usado por Páris — o de que "as qualidades que o distinguem são dons de Afrodite" (SCHÜLER, 1972, p.78) — para refutar as acusações que lhe são feitas por Heitor no canto III da mais antiga das epopéias homéricas (HOMERO, 1961, p.62-3), podemos também dizer que, na ode em análise, não ocorre ao $e u$ cantante mencionar que os atributos de Lice lhe foram transmitidos pelos antepassados.

Retornando a Gonzaga, devemos observar que ele igualmente não apresenta a beleza de Marília como decorrência de fatores hereditários, mas, de qualquer forma, ele prescinde da objetividade que a concessão de dotes físicos por uma divindade pressupõe. A beleza de Marília não precisa ter sido outorgada por Vênus para ser maior que a de Juno, que a de Minerva e, inclusive, que a da própria Vênus.

Visto, assim, que esta última não é, na lira 27, nem deusa do amor nem da beleza, podemos nos voltar para o significado do certame antigo dentro dessa composição. É fácil verificar que o poeta setecentista não está 
interessado no arcabouço mítico subjacente ao episódio do pomo da discórdia, que desempenha, dentro da mitologia, a função de explicar a origem de um fato histórico, o confronto entre os aqueus e os troianos decorrente da expansão do poderio daqueles a outros centros. Chegando essa expansão à Ásia Menor, é inevitável o choque com Tróia, dona de privilegiada posição geográfica, pois, estando situada a noroeste da Ásia Menor, constituía-se em estratégico ponto de cruzamento das rotas marítimas que ligavam a Ásia à Europa.

Nada disso, no entanto, interessa a Gonzaga, que tem como único objetivo, ao referir o episódio do pomo da discórdia - cuja vencedora nem sequer é nomeada —-, ressaltar, através da menção às deusas que dele participaram, a beleza de Marília, beleza tamanha que não só prescinde de subornos como os oferecidos a Páris por Vênus, Juno e Minerva para ser reconhecida como a maior, mas também não pode, por mais intenso que seja o esforço de seu amado nesse sentido, ser retratada.

Completamente diverso é o significado da referência — implícita no relato do apoio prestado por Vênus a Páris — feita por Horácio, na ode XV do livro I, antes transcrita, ao episódio em questão. Posto que, tal como Gonzaga, não apresente o mencionado certame como explicação mítica para um fato histórico, o venusino coloca-o em estreita vinculação com a guerra e a destruição de Tróia, não o dissociando, portanto — ao contrário do que faz o poeta árcade - , de seu contexto próprio.

Vênus, por sua vez, não figura, na composição de Horácio, como simples elemento a servir de parâmetro para a exaltação da beleza de outrem, como acontece na lira 27. Profundamente comprometida com Páris desde o momento em que este lhe concedera o título de a mais bela das imortais, Vênus é-nos mostrada, através do vaticínio de Nereu, como alguém que, consciente das obrigações assumidas, posta-se ao lado do príncipe troiano para auxiliá-lo em todas as necessidades.

O caráter premonitório das palavras de Nereu, pronunciadas após o rapto de Helena, remete-nos, especificamente, para o socorro prestado por Vênus a Páris durante a guerra de Tróia. Nesse sentido, ele faz-nos pensar no que acontece durante o duelo, narrado no canto III da Ilíada, entre Páris e Menelau, quando Vênus (ali denominada Afrodite), envolvendo seu protegido "em espessa névoa", carrega-o em seus braços e esconde-o da fúria do inimigo (HOMERO, 1961, p.71).

A ode de Horácio põe em relevo essa prontidão de Vênus para auxiliar Páris, prontidão que, embora baldada em face da invencibilidade dos fata/fera - mesmo a condição divina de Vênus não lhe possibilita subtrair o príncipe àquilo que os terríveis destinos determinaram - , contrasta, de forma sensível, com a inatividade que caracteriza a deusa na lira 27, em que o poeta a refere simplesmente para contrapor à sua, a beleza de Marília.

Passemos, agora, à transcrição da lira 25 de Gonzaga:

"De amar, minha Marília, a formosura 
não se podem livrar humanos peitos: adoram os heróis, e os mesmos brutos aos grilhões de Cupido estão sujeitos. Quem, Marília, despreza uma beleza a luz da razão precisa, e, se tem discurso, pisa a lei, que lhe ditou a natureza.

Cupido entrou no céu. O grande Jove uma vez se mudou em chuva de ouro; outras vezes tomou as várias formas de general de Tebas, velha e touro.

O próprio deus da guerra, desumano, não viveu de amor ileso: quis a Vênus e foi preso

na rede, que lhe armou o deus Vulcano.

Mas sendo amor igual para os viventes, tem mais desculpa ou menos esta chama: amar formosos rostos acredita, amar os feios, de algum modo infama. Quem lê que Jove amou, não lê nem topa que amou vulgar donzela: lê que amou a Dânae bela, encontra que roubou a linda Europa.

Se amar uma beleza se desculpa em quem ao próprio céu e terra move, qual é a minha glória, pois igualo, ou excedo no amor ao mesmo Jove? Amou o pai dos deuses soberano um semblante peregrino; eu adoro o teu divino,

o teu divino rosto, e sou humano" (GONZAGA, 1957, p.44-5).

Num poema que trata da universalização do sentimento amoroso e do primado do amor à beleza, a referência feita a Vênus, no $7^{\circ}$ verso da $2^{a}$ estrofe, tem um caráter duplamente paradigmático: de um lado, porque o sentimento que por ela nutre o deus da guerra ilustra bem o fato de todos os seres, humanos e divinos, estarem sujeitos aos grilhões de Cupido; de outro, porque o amor de Marte, estando dirigido a uma deusa cuja formosura não precisa vir expressa para que se saiba que existe, demonstra a impotência quase completa de todos face ao sentimento que a beleza desperta (dizemos que a impotência é quase completa porque, como o próprio Gonzaga afirma, no $5^{\circ}$ verso da $1^{\text {a }}$ estrofe, há pessoas que conseguem desprezar uma beleza).

No reconhecimento dessas duas facetas da menção feita a Vênus, subjazem tanto a identidade quanto a dessemelhança de certas características atribuídas à deusa por Gonzaga e por Horácio. 
Começando pela identidade, verificamos que ela se resume, basicamente, na beleza que ambos os poetas referem como traço peculiar a Vênus. Esse traço, implícito na lira em análise, é claramente expresso na pergunta formulada pelo poeta latino no $6^{\circ}$ verso da ode XVIII do livro I de seus Carmina. Após incitar seu amigo Varo a cultivar a videira e alertá-lo para "todos os pezares" — "omnia dura" (HORACE, 1954, p.30) — que esperam pelos abstêmios, indaga Horácio:

"Quis post uina grauem militiam aut pauperiem crepat?

Quis non te potius, Bacche pater, teque, decens Venus?" (HORACE, 1954, p.30).

"Quem, depois dos vinhos, queixa-se do pesado serviço militar ou da pobreza? Quem, antes, não (louva) a ti, pai Baco, e a ti, formosa Vênus?"

Para passarmos da identificação da semelhança para a da diversidade existente entre a Vênus gonzaguiana e a horaciana, cumpre estarmos bastante conscientes do modo como o poeta árcade universaliza, na lira 25, o sentimento amoroso: todos amam porque existe Cupido, que, agindo tanto na terra quanto no céu, sujeita todos — não só os heróis e os mesmos brutos mas também os deuses - aos seus grilhões. Conferindo, através da figura de Cupido, objetividade ao amor, o poeta consegue encontrar uma justificativa para o fato de ser tal sentimento comum a todos os seres.

Referido de forma tão objetiva quanto em Gonzaga, o sentimento amoroso não aparece, no entanto, em Horácio, como fruto da atuação de Cupido. A responsabilidade pelo desencadeamento do amor é imputada, como a ode XIX do livro I demonstra, a Vênus:

"Mater saeua Cupidinum

Thebanaeque iubet me Semelae puer et lasciua Licentia

finitis animum reddere amoribus.

Vrit me Glycerae nitor

splendentis Pario marmore purius; urit grata proteruitas

et uoltus nimium lubricus aspici. In me tota ruens Venus

Cyprum deseruit, nec patitur Scythas aut uersis animosum equis

Parthum dicere nec quae nihil attinent. Hic uiuum mihi caespitem, hic

uerbenas, pueri, ponite turaque

bimi cum patera meri:

mactata ueniet lenior hostia" (HORACE, 1954, p. 31-2). 
Traduzindo:

"A cruel mãe dos Desejos e o filho de Sêmele tebana e a lasciva Licença mandam-me voltar o coração para já fenecidos amores. Queima-me o brilho de Glicera, que reluz mais puro que o mármore de Paros; queima-me sua encantadora petulância e seu rosto demasiadamente perigoso de ser admirado. Vênus abandonou Chipre, precipitando-se toda sobre mim, e não consente que eu celebre os citas ou o corajoso parto com seus cavalos voltados e nada que não diga respeito a ela. Colocai aqui para mim, jovens, céspede vivo, (colocai) aqui ramos sagrados e incenso com uma taça de vinho de dois anos: imolada a vítima, (a deusa) virá mais suave".

A menção, nos versos 2 e 3, respectivamente, ao filho de Sêmele tebana, ou seja, a Baco, e à lasciva Licença não nos deve impedir de reconhecer que a maior responsável por esse voltar-se do poeta para já fenecidos amores é Vênus. Isso é evidente tanto pela posição primacial concedida à deusa, designada, no $1^{\circ}$ verso, de cruel mãe dos Desejos (a análise de outras odes permite-nos crer que ser citado em primeiro lugar corresponde, em Horácio, a possuir preeminência sobre os outros seres referidos), quanto pelas afirmativas contidas no verso 9 e seguintes, as quais, deixando, por completo, de lado as duas outras divindades, restringem-se unicamente à atuação de Vênus sobre o $e u$ cantante.

Diferentemente do que acontece em Gonzaga, portanto, é Vênus e não Cupido que, em Horácio, garante a objetividade do sentimento amoroso. O pequeno deus só aparece, nas odes do venusino, como um acompanhante de Vênus, como "o menino que está sempre encostado a ela" — "illi / semper haerentem puerum" — , segundo nos diz nos versos 9 e 10 da ode XXXII do livro I (HORACE, 1954, p.44).

Gonzaga, assim, destitui a deusa da função, em que Horácio a investe, de agente responsável pela eclosão do sentimento amoroso, transferindo tal função para Cupido. Essa destituição constitui, por si só, uma diferença marcante entre as posições de um e outro autor quanto a Vênus. Seu relevo, no entanto, não seria tão grande se, após efetivá-la, Gonzaga tivesse cometido à deusa outra atribuição. Isso, no entanto, não acontece. Embora a formosura da divindade desempenhe papel importante dentro da lira, Vênus não aparece, ali, como deusa da beleza: seus dotes físicos atraíram Marte - é bem verdade; mas não porque ela tivesse atuado nesse sentido e sim porque a lei, ditada pela natureza, de que devem todos amar a formosura, entrou, junto com Cupido, no céu, e o deus da guerra a ela se curvou. $\mathrm{Na}$ verdade, devemos observar que nenhuma referência é feita à condição divina de Vênus: a afirmação de que Cupido entrou no céu remete, especificamente, para os que foram submetidos à ação do deus - Júpiter e Marte - e não para aquelas que se tornaram alvo do sentimento deles; confirma isso o fato de que, na penúltima estrofe, fica esclarecido que pelo menos duas das transformações sofridas por Júpiter destinaram-se à conquista de simples mortais: mudado em chuva de ouro, ele amou a Dânae bela e, em touro, roubou a linda Europa. Sendo assim — cabe perguntar — o que impede um 
leitor não familiarizado com a mitologia de pensar que também Vênus, a exemplo do que acontece com as amadas de Júpiter, seja uma mulher e não uma deusa?

Portanto, da mesma forma que Dânae e Europa, Vênus é, na lira 25 , mero objeto do amor de um deus, o que lhe confere um caráter passivo que contrasta, sensivelmente, com a atuação marcante tida por ela na ode XIX do livro I de Horácio, na qual age, realmente, como deusa do amor.

O papel desempenhado por Vênus é, em síntese, idêntico ao de Marília, cujo amante, por sua vez, se identifica com Júpiter e com Marte na medida em que não é, como estes, sujeito do seu sentimento pela jovem, dado que considera o amor uma força cósmica, que objetiva, como vimos, através de Cupido.

Tão inativa quanto a das composições analisadas é a Vênus que figura nas liras $18,44,48,68,80,89$ e 92, cujo estudo foi por nós realizado em nossa dissertação de Mestrado. Vênus é, sem dúvida, considerada, nessas liras, uma divindade; no entanto, além de, por vezes, sua condição divina ser, de certa forma, esquecida, ela não age como deusa, assumindo uma posição passiva que contrasta, marcadamente, com a intensa atuação que tem nas odes de Horácio, nas quais ostenta toda a riqueza de atribuições que lhe eram cometidas no mundo mítico. A título de complementação, devemos dizer que, na ode III do livro I (HORACE, 1954, p.10-2), Vênus é referida como deusa protetora da navegação e, na ode IV do livro I (HORACE, 1954, p.12), como deusa da primavera e da fecundidade.

Que fatores - perguntamo-nos, seguindo a trilha do teórico espanhol Luzán — poderiam ser apontados no sentido de justificar o par antitético passividade/atividade referido acima? Seriam eles de ordem ambiental e/ou pessoal?

$\mathrm{O}$ primeiro elemento que nos ocorre, na tentativa de responder a essas perguntas, é de natureza cultural, dizendo respeito, especificamente, ao fator crença: Vênus não seria, em Horácio, ativa, deusa responsável por múltiplos encargos, porque se acreditava, à época, que ela de fato existia? E, ao contrário, a passividade que a caracteriza em Gonzaga não seria decorrente do fato de que, no século XVIII, essa modalidade de crença era impensável? Dois tipos de dados — um de ordem textual, o outro, contextual — interpõem-se à validade dessa hipótese; o primeiro deles está presente nas próprias liras do poeta árcade, nas quais outras divindades mitológicas agem, muito embora sua existência seja tão incrível quanto a de Vênus; o segundo remete-nos para o século I a.C., época em que viveu Horácio e na qual a crença naquelas divindades estava profundamente minada pela infiltração, em Roma, de correntes filosóficas gregas e de cultos religiosos orientais.

Segundo pensamos, foi justamente a ameaça iminente de uma total descrença nos membros do panteão greco-romano um dos fatores determinantes da intensa atuação tida por Vênus nas odes de Horácio. Dizemos um dos e não $o$ fator determinante porque o sobrepuja um dado pessoal, ou seja, a intenção do poeta de auxiliar Augusto na tarefa a que este 
se propusera de, fomentando as antigas crenças, fazer voltar a Roma a moralidade que outrora a caracterizara. Mostrar Vênus agindo no cumprimento de todas as funções em que o homem mítico a investira equivale a dar um grande passo para a consecução do objetivo do Princeps, a quem Horácio de encontrava ligado através da inteligente mediação de Mecenas e que velava, com especial predileção, pela literatura, justamente porquanto via nela um meio seguro para atingir seus escopos políticos.

É igualmente nos desígnios do poeta que vamos encontrar a causa fundamental da passividade de Vênus nas liras gonzaguianas. Ao introduzi-la em suas composições, o vate árcade não tem seu interesse centrado na própria deusa, valendo-se dela como termo de comparação ou como elemento paradigmático que lhe propicia representar, de forma mais cabal, realidades outras que não ela mesma. A beleza de Vênus, por exemplo, serve-lhe, na maioria das liras acima citadas, para melhor enaltecer os predicados da amada, Marília. Fatos constitutivos da história da deusa fornecem-lhe, por outro lado, elementos capazes de exemplificar asserções ou de caráter abrangente - como a relativa à atuação da fortuna na vida de todos os seres (lira 68) (GONZAGA, 1957, p.122-3) — ou ligadas especificamente a Marília - como ocorre na lira 80 (GONZAGA, 1957, p.143-4), na qual a jovem deve tomar a lacrimosa intervenção de Vênus a favor dos troianos como um modelo a ser seguido na tentativa de livrar o amado da situação penosa em que ele se encontra. A criação de um relacionamento nada positivo entre a deusa e Cupido possibilita-lhe ainda, na lira 18 (GONZAGA, 1957, p.29-30), dar o devido realce ao tipo de atitude que Marília adota com respeito ao eu lírico.

Utilizada, assim, não como um fim, mas como um meio para se chegar a outras realidades, é passiva a Vênus das liras de Gonzaga. E, em o sendo, é uma figura nova, que, contrastando com a Vênus atuante das odes horacianas, constitui a expressão prática do conceito de mimese indireta como criação.

\section{BIBLIOGRAFIA}

ELYSIO, Filinto. Carta ao senhor F. J. M. de B. In: Obras completas. 2 ed. Paris, A. Bobée, v.1, 1817.

GARÇÃO, Correia. Dissertação III. In: Obras completas. Lisboa, Sá da Costa, v. 2, 1958.

GONZAGA, Tomás Antônio. Obras completas. Rio de Janeiro, I. N. L., v. 1, 1957.

HOMERO. Ilíada. São Paulo, Difusão Européia do Livro, 1961.

HORACE. Odes et épodes. 5. ed. rev. et cor. Paris, Les Belles Lettres, 1954. 
De arte poetica liber. In:

Epitres. 4. ed. Paris, Les Belles Lettres, 1961.

LUZÁN, Ignacio de. La poética o reglas de la poesía en general y de sus principales especies. Ediciones de 1737 y 1789. Madrid, Cátedra, 1974.

SCHÜLER, Donaldo. Aspectos estruturais na Ilíada. Porto Alegre, UFRGS, 1972. 